\title{
Determine a methodology for calculating the needed fresh air
}

\author{
Peter Kapalo ${ }^{a}$, Silvia Vilčeková ${ }^{b}$, Florin Domnita ${ }^{c}$, Orest Voznyak ${ }^{d}$ \\ ${ }^{a, b}$ Technical University of Kosice, Faculty of Civil Engineering, Vysokoskolska 4, 04200 Kosice, Slovakia \\ ${ }^{c}$ Technical University of Cluj-Napoca, Faculty of Buiding Services Engineering, 21 Decembrie 1989 St. 128-130, 400114 Cluj-Napoca, Romania \\ ${ }^{d}$ National University - Lviv Polytechnic, Lviv, Ukraine
}

\begin{abstract}
By improving thermal properties and air tightness of buildings, there is a change of indoor air quality in buildings - without any ventilation (natural or mechanical) there is a significant deterioration of indoor air quality. In low-energy and passive houses about $80 \%$ of total energy consumed for heating is used to heat the fresh air needed for occupants.

The aim of the paper is to determine a methodology for calculating the needed airflow rate (including fresh air) in an occupied room, based on carbon dioxide measurement and calculation, in order to maintain a comfortable level of indoor air quality. The calculated airflow rate should optimize the investment and the operating costs of HVAC equipment. In the work calculation methods used to determine the ventilation airflow rate are analyzed. A methodology for calculating the ventilation airflow rate for a room with people inside by using the measured values of carbon dioxide concentration is presented. The connection between carbon dioxide concentration and ventilation airflow rate is verified by experimental measurements.

This methodology is applicable in Slovakia because it complies with all current standards. The result obtained by using this calculation method is almost the same with the results achieved from experimental measurements. To confirm the results, we present a case study of an office with occupants, in which the ventilation airflow rate calculation method is applied.
\end{abstract}

Keywords: ventilation; airflow rate; legislative; carbon dioxide $\left(\mathrm{CO}_{2}\right)$, concentration.

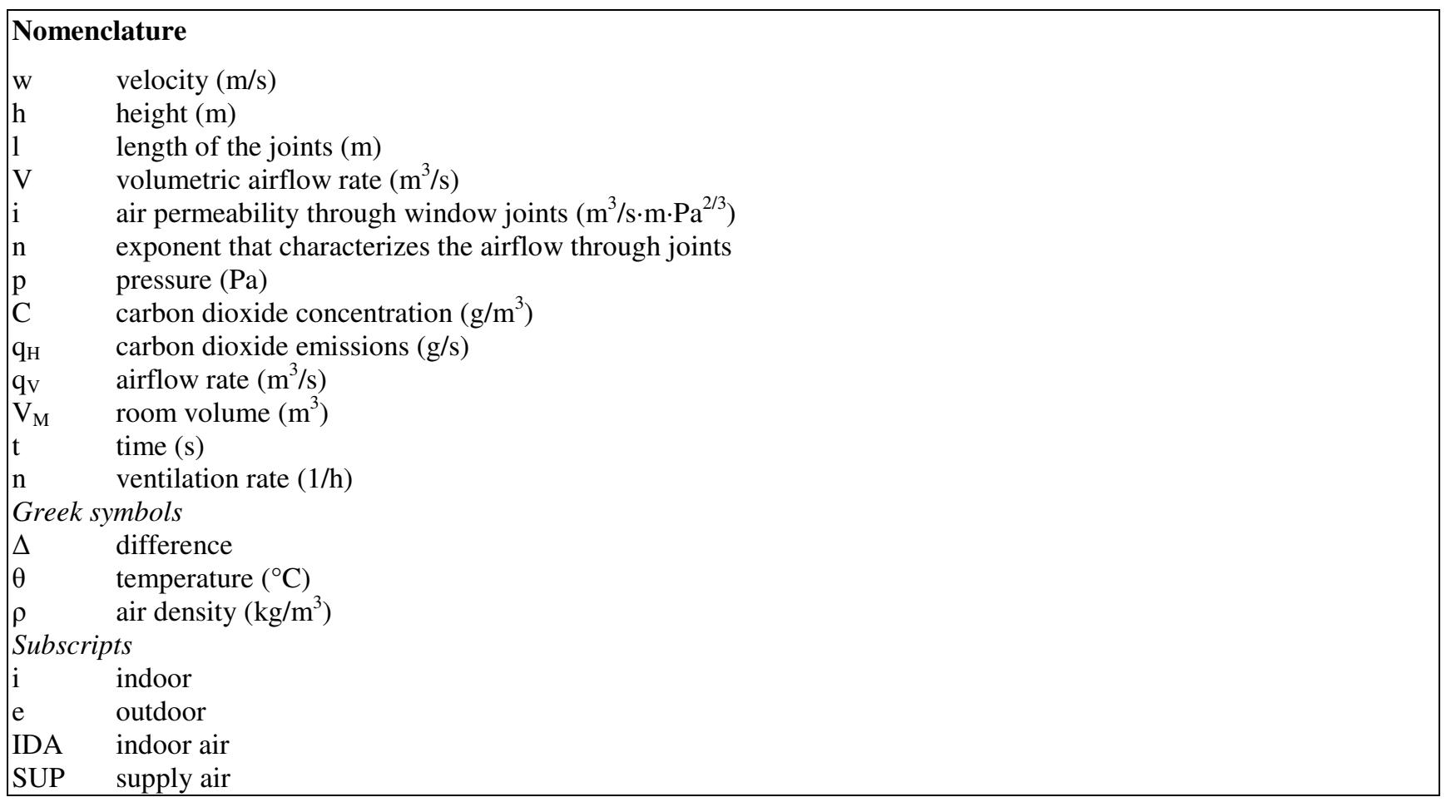

Corresponding author: Peter Kapalo. E-mail address: peter.kapalo@tuke.sk

http://dx.doi.org/10.3846/enviro.2014.264

(C) 2014 The Authors. Published by VGTU Press. This is an open-access article distributed under the terms of the Creative Commons Attribution License, which permits unrestricted use, distribution, and reproduction in any medium, provided the original author and source are credited. 
Abbreviations

$\mathrm{CO}_{2} \quad$ carbon dioxide

HVAC heating, ventilation and air conditioning

C-AQ-0001R sensor unit for $\mathrm{CO}_{2}$

S-3541 thermo-hydrometer

\section{Introduction}

In recent years, the standard of living in Europe increased significantly. The direct consequences are increases in energy consumption of buildings and a negative impact on the environment. Larger number of home appliances cause greater energy consumption. In some European countries, approximately $40 \%$ of energy is consumed in buildings. In construction industry increasing pressure to construct low energy buildings is exerted. Energy effective houses do not present the new definition of projection but it is more improving of attested processes and adaptation to new requests [1]. According to EuroACE [2], 57\% of consumed energy in a building is used for heating, $25 \%$ for heating hot water, $11 \%$ for lighting and electrical appliances and $7 \%$ for cooking.

Nowadays, the priority is to build-up low energy buildings with controlled ventilation. Importance of ventilation in heated and tight building is documented by questionnaires, where the respondents had the opportunity to comment on the issue of office buildings indoor environment. 177 persons filled out a questionnaire, $43 \%$ of them were women and $57 \%$ men, with the age of 20 - 30 years (73\%), $30-40$ (20\%), $40-50(3 \%)$ and over 50 years (4\%) [3].

The respondents also expressed their opinion on the indoor air quality by giving evaluation marks from 1 to 10 ( 1 for the poorest and 10 for the best indoor air quality). Most of the respondents considered indoor air quality as very good as they gave marks from 8 to10 (Fig. 1).

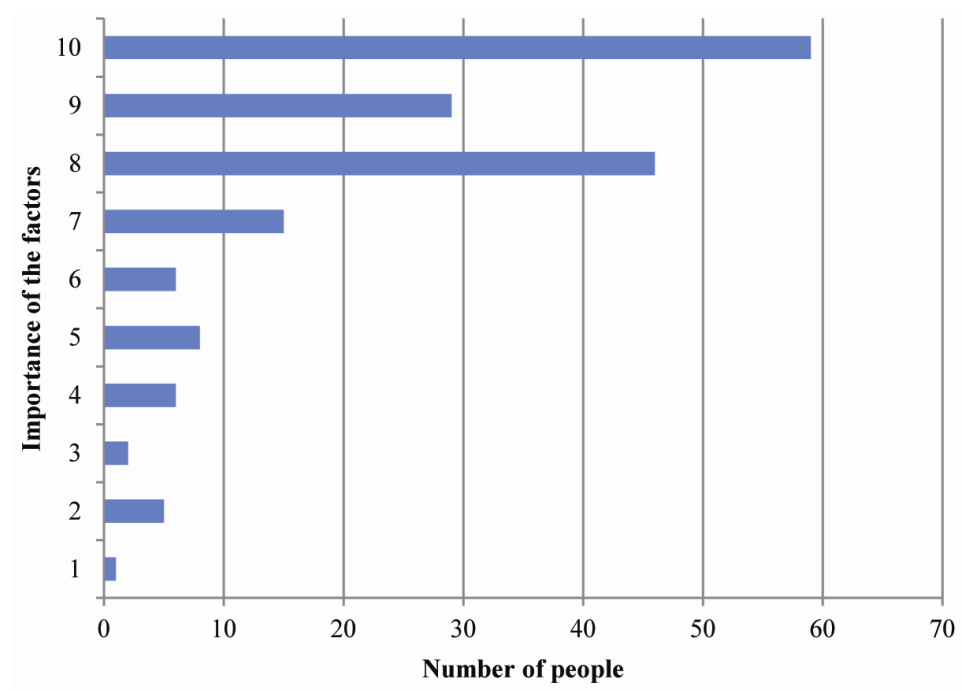

Fig. 1. Indoor air quality [3]

To establish the necessary ventilation rate the theoretical knowledge can be used, based on the theory of determining volumetric airflow rate based on the quantity of gaseous pollutants and $\mathrm{CO}_{2}$ released inside a room. Experimental measurements of the concentration of $\mathrm{CO}_{2}$ were carried out in winter in several selected rooms. On the basis of measured concentration of $\mathrm{CO}_{2}$ the needed fresh air ventilation rate that meets sanitary requirements, as well as the intensity of ventilation rate in the room can be calculated.

Intensity of air exchange in the tested room generally can be defined by calculations and measurements. In this work a room with natural ventilation is examined.

\section{Data/Methods}

\subsection{Carbon dioxide as a result of respiration}

The human body of an adult contains approximately $12.6 \mathrm{~kg}$ of carbon. Carbon is an element with a content of about $18 \%$ in the human organisms. Redundancy of carbon atoms is removed from organism in the process of respiration in the form of carbon dioxide. Energy released in such way is spent to maintain the vital processes in human organism.

The carbon dioxide is a gas without color and odor and it is also contained in the atmospheric air. The exhaled air contains (Table 1) approximately 4\% carbon dioxide [4]. Such concentration is non-toxic for humans. However, in case of higher concentrations there are typical syndromes like hyperventilation, higher blood pressure and pulse. Even more increased concentration of carbon dioxide causes serious damages to the organism. At $10 \%$ concentration a blackout occurs and it comes to death caused by suffocation. 
Table 1. Composition of inhaled and exhaled air for healthy adult humans [4]

\begin{tabular}{lll}
\hline Breathing substance & Inhaled air $(\%)$ & Exhaled air $(\%)$ \\
\hline Oxygen & 20.96 & $15.4-17$ \\
Carbon dioxide & 0.04 & $4-5.6$ \\
Nitrogen & 78 & 78 \\
Other gases & 1 & 1 \\
\hline
\end{tabular}

At a normal rate of breath, an adult can inhale 2.5 liters of air or even more. After the exhalation approximately 0.5 liters of air remains in lungs and bronchi. This volume is called the residual lung volume. Respiratory rate is the number of breaths per minute and is depending on age. The respiratory rate for a newborn is from 40 up to 45 inhalations/exhalations per minute, for a child 25 up to 30 inhalations/exhalations per minute and for an adult from 16 up to 20 inhalations/exhalations per minute. Accelerated breathing is more than 20 inhalations/exhalations per minute for an adult person and it can increase up to 100 in the case of a high demand of oxygen (i.e. during intense physical or psychical loading). Reduced respiration is less than 12 breaths per minute (Table 2).

Table 2. Calculated carbon dioxide flow rate for different degrees of breathing

\begin{tabular}{|c|c|c|c|c|c|c|}
\hline \multirow{2}{*}{$\begin{array}{l}\text { Volume of } \\
\text { inhalation/exhalation } \\
\text { [1] }\end{array}$} & \multirow{2}{*}{$\begin{array}{l}\text { Intensity of } \\
\text { respiration } \\
{[1 / \mathrm{min}]}\end{array}$} & \multicolumn{2}{|c|}{$\begin{array}{l}\text { Airflow rate } \\
\text { inhalation/exhalation }\end{array}$} & \multicolumn{3}{|c|}{ Carbon dioxide flow rate } \\
\hline & & {$[1 / \mathrm{s}]$} & {$\left[\mathrm{m}^{3} / \mathrm{h}\right]$} & {$\left[\mathrm{m}^{3} / \mathrm{h}\right]$} & {$[\mathrm{kg} / \mathrm{h}]$} & {$[\mathrm{mg} / \mathrm{s}]$} \\
\hline 0.5 & 12 & 0.10 & 0.36 & 0.014 & 0.028 & 7.86 \\
\hline 0.5 & 13 & 0.11 & 0.39 & 0.016 & 0.031 & 8.51 \\
\hline 0.5 & 14 & 0.12 & 0.42 & 0.017 & 0.033 & 9.17 \\
\hline 0.5 & 15 & 0.13 & 0.45 & 0.018 & 0.035 & 9.82 \\
\hline 0.5 & 16 & 0.13 & 0.48 & 0.019 & 0.038 & 10.47 \\
\hline 0.5 & 17 & 0.14 & 0.51 & 0.020 & 0.040 & 11.13 \\
\hline 0.5 & 18 & 0.15 & 0.54 & 0.022 & 0.042 & 11.78 \\
\hline 0.5 & 19 & 0.16 & 0.57 & 0.023 & 0.045 & 12.44 \\
\hline 0.5 & 20 & 0.17 & 0.60 & 0.024 & 0.047 & 13.09 \\
\hline
\end{tabular}

A healthy adult has a respiratory flow rate from 7.5 to 8 litres of air per minute at approximately 15 breathings per minute. The breathing frequency will increase during physical effort, when a large volume of oxygen is needed [4].

According to the $\mathrm{CO}_{2}$ parameters, lung volume and intensity of breathing, there are calculated the $\mathrm{CO}_{2}$ mass flow rates for different degrees of breathing (Table 3).

Table 3. Calculated $\mathrm{CO}_{2}$ mass flow rates for different degrees of intensity of breathing and for 0.51 of inhalation-exhalation

\begin{tabular}{llllllllll}
\hline Intensity of breathing, [1/min] & 12 & 13 & 14 & 15 & 16 & 17 & 18 & 19 & 20 \\
\hline Mass flow rate of $\mathrm{CO}_{2,}[\mathrm{mg} / \mathrm{s}]$ & 7.86 & 8.51 & 9.17 & 9.82 & 10.47 & 11.13 & 11.78 & 12.44 & 13.09 \\
\hline
\end{tabular}

It can be seen that the $\mathrm{CO}_{2}$ mass flow rate increases linearly with breathing intensity.

\subsection{The calculation of needed fresh airflow rate in a populated room}

During the research, in the selected room (office with one occupant), the following indoor environment parameters were measured: air temperature, relative humidity and carbon dioxide concentration.

The dimensions of the office, where the experimental measurements were carried out, are:

- length: $\quad 5.63 \mathrm{~m}$

- width: $\quad 3.40 \mathrm{~m}$

- height: $\quad 2.72 \mathrm{~m}$

The office window has the following dimensions:

- height: $\quad 1.75 \mathrm{~m}$

- width: $\quad 1.10 \mathrm{~m}$ 


\subsection{Infiltration airflow rate}

Volumetric airflow rate through window joints can be determined [5] from the Eqn (1):

$$
V=i \cdot l \cdot \Delta p^{n}\left[\mathrm{~m}^{3} / \mathrm{s}\right]
$$

where: $V$ - volumetric airflow rate, $\mathrm{m}^{3} / \mathrm{s} ; i$ - air permeability through window joints, $\mathrm{m}^{3} / \mathrm{s} \cdot \mathrm{m} \cdot \mathrm{Pa}^{2 / 3} ; l-$ length of the joints, $\mathrm{m}$; $n$ - exponent that characterizes the airflow through joints, commonly $n=2 / 3 ; \Delta p$ - differential pressure due to the air temperature difference between indoor and outdoor and the external wind pressure, $\mathrm{Pa}$.

Differential pressure due to air temperature difference between indoor and outdoor and the external wind pressure [5], is given by the Eqn (2):

$$
\Delta p=h \cdot g \cdot\left(\rho_{e}-\rho_{i}\right)+0,5 \cdot w^{2} \cdot \rho_{e}[\mathrm{~Pa}]
$$

where: $\theta_{\mathrm{i}}$ - indoor air temperature, ${ }^{\circ} \mathrm{C}, \theta_{\mathrm{i}}=23{ }^{\circ} \mathrm{C} ; \theta_{\mathrm{e}}-$ outdoor air temperature ${ }^{\circ} \mathrm{C}, \theta_{\mathrm{e}}=7{ }^{\circ} \mathrm{C} ; \rho_{\mathrm{i}}-$ indoor air density, kg/m $\mathrm{m}^{3}$, $\rho_{\mathrm{i}}=1.153 \mathrm{~kg} / \mathrm{m}^{3} ; \rho_{\mathrm{e}}-$ outdoor air density, $\mathrm{kg} / \mathrm{m}^{3}, \rho_{\mathrm{e}}=1.219 \mathrm{~kg} / \mathrm{m}^{3} ; h$ - window height, $\mathrm{m} ; w-$ medium wind velocity $\mathrm{m} / \mathrm{s}$, $w=4.16 \mathrm{~m} / \mathrm{s}$.

This calculation provides the boundary conditions needed for measuring the carbon dioxide concentration. The result for infiltration airflow rate in the tested office is 0.205 1iters per hour.

\section{Results and discussion}

\subsection{Carbon dioxide concentration}

Carbon dioxide concentration in the room air [6], [7], [8] is calculated according the Eqn (3):

$$
C_{I D A}=C_{S U P}+\frac{q_{H}}{q_{V}} \cdot\left\{1-\exp \left[\left(\frac{-q_{V}}{V_{M}}\right) \cdot t\right]\right\}\left[\mathrm{g} / \mathrm{m}^{3}\right]
$$

where: $C_{I D A}$ - carbon dioxide concentration in indoor air at the time $\mathrm{t}, \mathrm{g} / \mathrm{m}^{3} ; C_{S U P}-$ carbon dioxide concentration in supply air at a time $\mathrm{t}, \mathrm{g} / \mathrm{m}^{3} ; q_{H}$ - carbon dioxide emissions inside the room from the human source, g/s; $q_{V}-$ airflow rate required for room ventilation, $\mathrm{m}^{3} / \mathrm{s} ; V_{M}-$ room volume, $\mathrm{m}^{3} ; t-$ time, $\mathrm{s}$.

Eqn (3) provides values for carbon dioxide concentration in the room air by means of Table 2 and for carbon dioxide concentration in supply air, $C_{S U P}=420 \mathrm{ppm}$, measured outdoor. For different values of respiration intensity the results of the calculations together with measurements (bold line) are shown in Figure 2. By comparing the measured to the calculated values, the most accurate carbon dioxide production is determined.

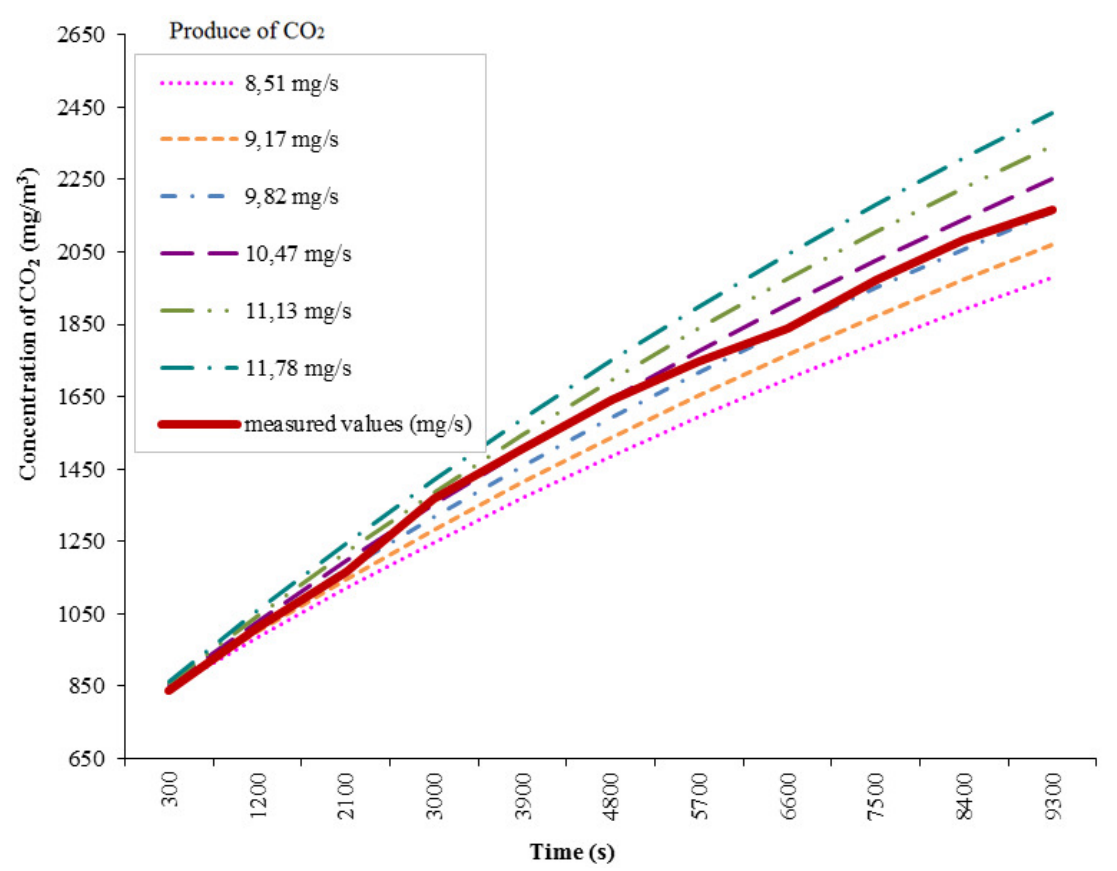

Fig. 2. Determination of carbon dioxide production by comparing measured and calculated values 
It can be concluded that the releases of carbon dioxide from human occupants with a breathing intensity of $151 / \mathrm{min}$ are almost the same according to the calculated and measured values (Fig. 2). This value corresponding to the carbon dioxide produce $q_{H}=9.82 \mathrm{mg} / \mathrm{s}$.

$$
q_{V}=\frac{q_{H}}{C_{I D A}-C_{S U P}}\left[\mathrm{M}^{3} / \mathrm{S}\right]
$$

By using the Eqn (4) to calculate the needed indoor airflow rate, the result is $n=0.681 /$ hour, almost similar to that obtained by graphical method.

\subsection{Measurement of carbon dioxide production}

In order to determine the values of carbon dioxide concentration, a $\mathrm{CO}_{2}$ sensor unit $\mathrm{C}$-AQ-0001R was used. To measure the air temperature and relative humidity a thermo-hydrometer measuring device S-3541 was used.

Figure 3 shows the graphic variation (depending on time) of the following measured parameters: $\mathrm{CO}_{2}$ concentration, indoor air temperature and relative humidity.

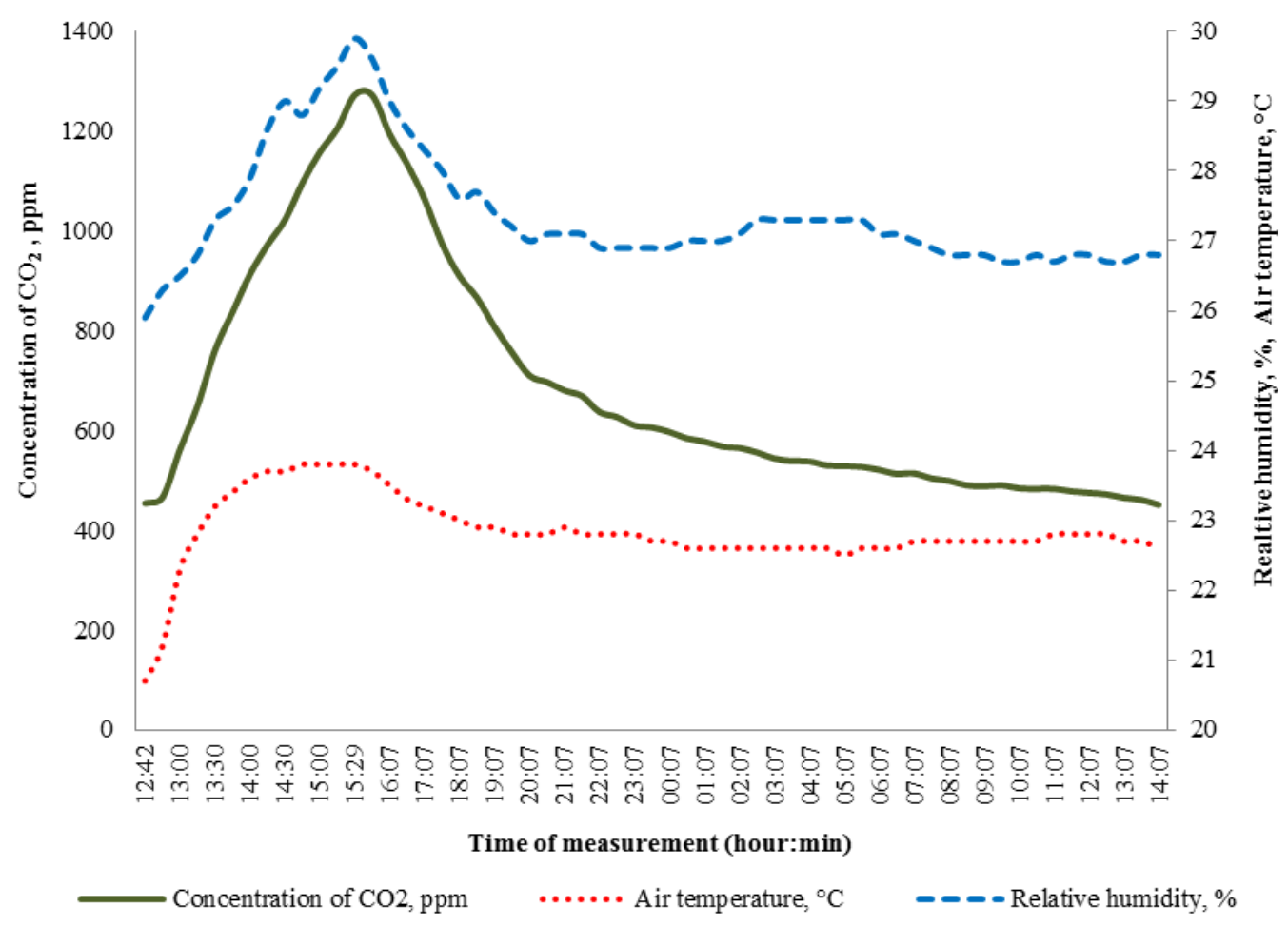

Fig. 3. Measured $\mathrm{CO}_{2}$ concentration, indoor air temperature and relative humidity

The waveforms of measured values of $\mathrm{CO}_{2}$ concentration and indoor air relative humidity are increasing significantly until 16 o'clock and after that are slowly decreasing. The increasing and decreasing of indoor air temperature is not similar to the relative humidity. After reaching a maximum $\mathrm{CO}_{2}$ concentration at 16 o'clock, the room was abandoned and the releases of $\mathrm{CO}_{2}$ stopped. The decreasing of $\mathrm{CO}_{2}$ concentration is caused by infiltration and natural ventilation.

\subsection{Indoor airflow rate calculation}

Required indoor air quality is given by standards STN EN 13779 [6]. Processed data are presented in Table 4.

Table 4. $\mathrm{CO}_{2}$ concentration level in occupied rooms and outdoor airflow according to STN EN 13779 [6].

\begin{tabular}{lllll}
\hline Category & $\begin{array}{l}\mathrm{CO}_{2} \text { concentration above outdoors level } \\
(\mathrm{ppm}) \\
\end{array}$ & $\begin{array}{l}\text { Outdoor airflow per person (non smoker) } \\
(\mathrm{l} /(\mathrm{s} \cdot \text { person }))\end{array}$ & $\begin{array}{l}\text { Outdoor airflow per one m } \mathrm{m}^{2} \text { of floor area } \\
\left(1 /\left(\mathrm{s} \cdot \mathrm{m}^{2}\right)\right)\end{array}$ \\
\hline IDA 1 & $\leq 400$ & 350 & Standard value & Standard value \\
IDA 2 & $400 \div 600$ & 500 & 20 & 0.83 \\
IDA 3 & $600 \div 1000$ & 800 & 12.5 & 0.55 \\
IDA 4 & $>1000$ & 1200 & 8 & 0.28 \\
\hline
\end{tabular}


It can be seen that the required value for indoor airflow rate must be chosen in such a way, that the concentration of $\mathrm{CO}_{2}$ never surpasses $1000 \mathrm{ppm}$.

From the values obtained by calculation we calculated the required intensity of ventilation for a room with a given number of persons located in it. The requirement which was necessary to meet was the maximum concentration of $\mathrm{CO}_{2}$ in the room $\mathrm{C}_{\mathrm{IDA}}=1000 \mathrm{ppm}-$ see Figure 4 .

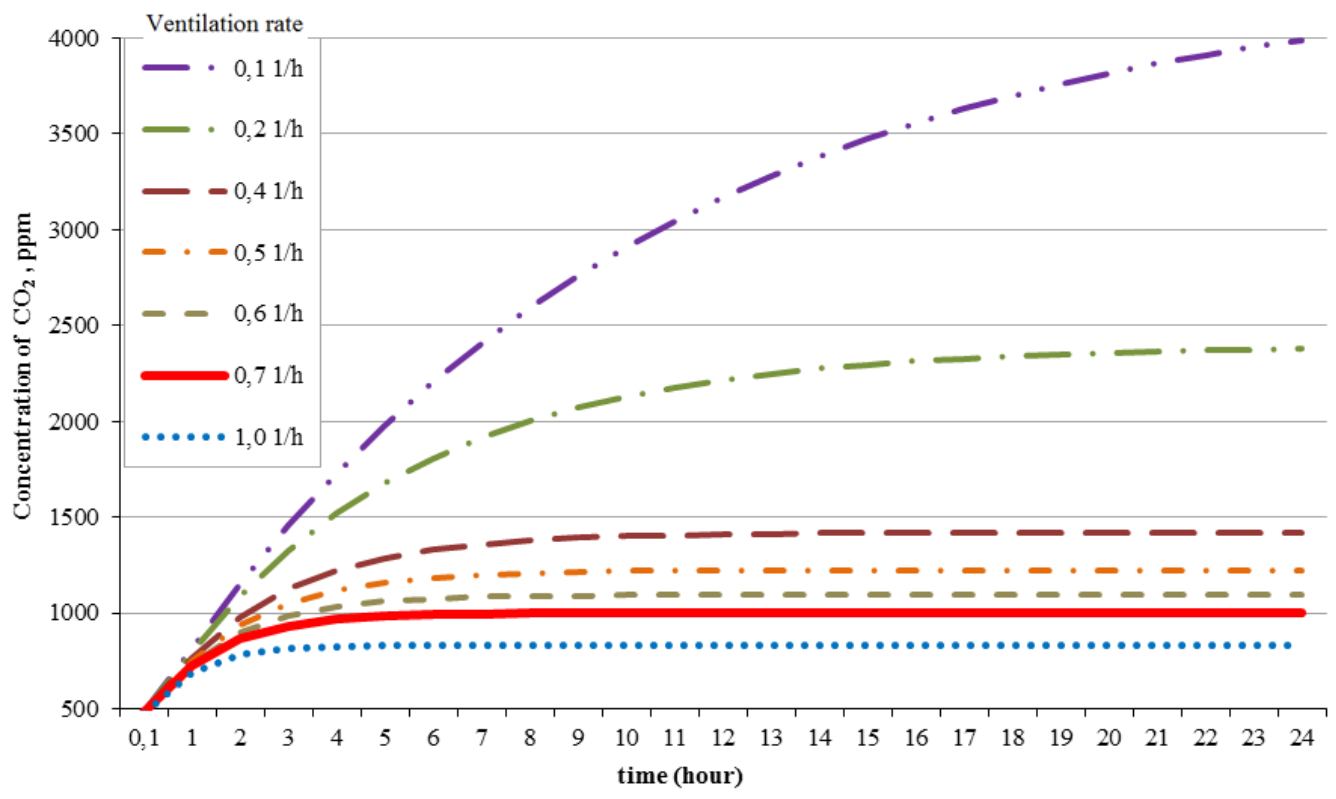

Fig. 4. Graphic method to determine indoor airflow rate

In our case it is the curve of concentrations marked in bold (second from the bottom) with an intensity of ventilation of $n=0.71 / \mathrm{h}$.

\section{Conclusions}

The aim of the research is to determine the needed exchange of indoor air on the basis of combined calculation and experimental method (measurement of the release of carbon dioxide from room occupants). During the experiment, the studied room was occupied with persons who produced $9.82 \mathrm{mg} / \mathrm{s}$ of carbon dioxide, based on measurement results.

In order to ensure a healthy indoor climate, by calculation method, an indoor airflow rate of $0.681 /$ hour is required. According to standard EN 13779 [6], the needed indoor airflow rate can be determined according to the production of pollutants inside the tested room, in our case study the release of carbon dioxide from room occupants. On the basis of measured concentration from $\mathrm{CO}_{2}$ (Fig. 4) the result value for indoor airflow rate is $0.71 /$ hour (bold line), accordingly the experimental $\mathrm{CO}_{2}$ results have shown good congruence of air change rate with the calculated valid standards.

The standard EN 13779 [6] is satisfactory according to research for determination ventilation rate.

\section{Acknowledgements}

This article was elaborated in the framework of the project VEGA 1/0405/13 and KEGA 052TUKE-4/2013.

\section{References}

[1] Sedláková, A.; Vojtuš, J.; Burdová, E. K. 2012. Design of consumer model and environmental assessment of used building materials, in $12^{\text {th }}$ International Multidisciplinary Scientific GeoConference, SGEM 2012-5, 235-242. Albena. ISSN 1314-2704.

[2] EuroACE. 2004. Towards Energy Efficient Buildings in Europe. Final report June, 2004.

[3] Pilipová, I. 2013. Respondents' comfort in building with smart elements, Young Scientist 2013: The 5th PhD. Student Conference of Civil Engineering and Architecture: Herlany, April 10-12, 2013. Košice: TU, 2013 S. 12. ISBN 978-80-553-1305-4.

[4] Voigt, E.; Pelikan, J. 2010. $\mathrm{CO}_{2}$-Measurement during Ventilation. Dräger Medizintechnik GmbH. Lübeck. ISBN 3-926762-38-1.

[5] Gebauer, G.; Rubínová, O.; Horká, H. 2005. Ventilation Technic. ERA group, spol. s.r.o., Brno. ISBN 80-7366-027-X.

[6] STN EN 13779. 2005. Ventilation in non-residential buildings. General requirements for ventilation and air conditioning equipment. 2005

[7] Košičanová, D.; Nagy, R.; Šenitková, I. 2011. Transmission and distribution of pollutants in relation to the environment. Technical University of Kosice, SvF-2011. ISBN 978-80-553-0829-6.

[8] Persily, A. 1997. Evaluating building IAQ and ventilation with indoor carbon dioxide. Transactions American society of heating refrigerating and air conditioning engineers, p. 193-204, ASHRAE. 